5-1-2005

\title{
Presence and Image Quality: The Case of High-Definition Television
}

Cheryl C. Bracken

Cleveland State University, c.bracken@csuohio.edu

Follow this and additional works at: https://engagedscholarship.csuohio.edu/clcom_facpub

Part of the Communication Commons

How does access to this work benefit you? Let us know!

Publisher's Statement

This is an Author's Accepted Manuscript of an article published in Media Psychology, 2005, available online: http://www.tandfonline.com/10.1207/S1532785XMEP0702_4.

\section{Recommended Citation}

Bracken, C. C. (2005). Presence and Image Quality: The Case of High-Definition Television. Media Psychology, 7(2), 191-205. https://doi.org/10.1207/S1532785XMEP0702_4

This Article is brought to you for free and open access by the School of Communication at EngagedScholarship@CSU. It has been accepted for inclusion in Communication Faculty Publications by an authorized administrator of EngagedScholarship@CSU. For more information, please contact library.es@csuohio.edu. 


\title{
Presence and Image Quality: The Case of High-Definition Television
}

\author{
Cheryl Campanella Bracken
}

\begin{abstract}
Previous research has demonstrated that form variables can increase television viewers' sense of presence. The current broadcasting of high-definition television (HDTV) programming makes testing this relation between form and presence possible in a new context, image quality. In this experiment. television viewers watched either HDTV or standard-definition television images and then rated their viewing experience on a pencil-and-paper questionnaire. The results demonstrate that HDTV provided viewers with a greater sense of presence than the current standard, thus providing empirical evidence for the claim that improved image quality will lead to television viewers' experiencing presence. Additionally, the results suggest that with the coming of HDTV, sensations of presence will be both stronger and more common.
\end{abstract}

The quality of television images watched in America's living rooms is about to change dramatically with the conversion to high-definition television (HDTV), currently scheduled for 2007 . There are many speculations about the changes that HDTV will bring to our viewing experience, including those about viewers becoming tired from the additional visual information, and about the changes in viewing habits. Krugman (1983) suggested that HDTV will provide television audiences with such intense viewing experiences that audience members will want to continue to watch their old standard television set for more relaxing viewing. It seems likely that content may also play a part in the selection of image quality. However, although there are studies that explore television viewers' preferences for HDTV, there has not been an empirical investigation that has explored the psychological responses to improvements in image quality. In this study, I explored 
the relation between improved image quality (with HDTV) and the amount of presence reported by television viewers.

\section{PRESENCE}

First introduced as telepresence by Minsky (1980) and referring to a physical sense of "being there" in a remote, mediated location, presence today has been investigated by researchers in a diverse set of disciplines, including communication, psychology, computer science, and engineering. Recently, presence has been extended from research on virtual reality to more traditional media, and with the exception of film (where a concept similar to presence is known in film studies as the diegetic effect; Burch, 1979), it has not been widely studied by empirical media scholars.

Presence has been accepted as a psychological phenomenon (Botella, Baños, \& Alcañiz, 2003: Schubert, Friedman, \& Regnebrecht, 2001), but there are differences in how it has been conceptualized. Previous conceptualizations have included a sense of being there or being inside a mediated environment (Sheridan. 1992; Slater, \& Wilbur, 1997). While presence was initially conceptualized as a unidimensional construct, researchers have more recently come to understand it as "a variable with various levels and dimensions" (Biocca \& Delaney, 1995, p. 62), and presence was conceptualized as a multidimensional concept by Lombard and Ditton (1997). ${ }^{1}$ The conceptualizations were combined into an overarching definition of presence as a "perceptual illusion of nonmediation" (Lombard \& Ditton. 1997, Presence Explication, I2).

Although this definition has been widely accepted, there continue to be additional modifications. There has been a debate on whether presence research should be limited to mediated interactions; Lee (2004) argued that it should be extended to include nonmediated interaction. However, the majority of presence researchers argue that presence research should be restricted to mediated interactions (David. 2004).

In an effort to create agreement among presence researchers, an online discussion helped to establish a inclusive definition of presence:

A psychological state or subjective perception in which even though part or all of an individual's current experience is generated by and/or filtered through human-made technology, part or all of the individual's perception fails to accurately acknowledge the role of the technology in the experience. (Lombard, 2000, \&2)

According to Lombard, Reich, Grabe, Bracken, and Ditton (2000), the term perceptual indicates that this phenomenon involves continuous (real-time) responses of the human sensory, cognitive, and affective processing systems of a per- 
son's environment. The illusion of nonmediation occurs when a person overlooks or fails to perceive the existence of a medium or a technology in his or her communication environment and responds as if the medium were not there. It should be noted that this illusion does not represent a perceptual or psychological malfunction or psychosis in which the mediated experience is consciously confused with what is nonmediated or real. There is evidence that when asked, users of any current or likely future medium can accurately report that they are using a medium (Lombard \& Ditton, 1997). As a perceptual illusion, presence is a property of a person, and because it results from an interaction among formal and content characteristics of a medium and characteristics of the media user, it can and does vary across individuals and across time for the same individual.

Presence is typically measured through subjective assessment (which has been shown to be reliable and valid; see Kim \& Biocca, 1997). Although some have suggested other useful simultaneous indicators, which include physiometric (e.g., heart rate see Dillon, Keogh. Freeman. \& Davidoff, 2001) measures and task performance (e.g.. secondary reaction time; see Barfield \& Weghorst, 1993), a correlation between the posttest subjective measures and physiological measures has not been confirmed.

\section{Presence and Television}

Prior studies have provided evidence that television, although not as immersive as virtual reality environments, can induce a sense of presence (Kim \& Biocca, 1997; Lombard et al., 2000). In an experiment examining participants' presence responses to the point-of-view movement camera technique (in which the viewers saw the action through the eyes of the character or real-life actor), participants viewed either a large (46-in. projection) or small (12-in.) television screen (Lombard et al., 2000). They found that participants who watched the large screen television reported feeling a greater "sense of physical movement," enjoyment, and involvement than viewers who watched the scenes on a small screen television (p. 92).

Additionally, traditional media effects have been influenced by the experience of a sense of presence during television viewing. For example, Kim and Biocca (1997) studied the impact of the experience of a sense of presence on the perceptions of the persuasive nature of a televised infomercial. They defined presence as the "feeling of being a part of the phenomenal environment created by the television set" and found that participants who reported a greater sense of presence felt more confident in their choice of brand. Other media effects that have been examined include source credibility (Bracken, Neuendorf, \& Jeffres, 2003). The role of screen size and its effect on both the sensations of presence and the perceptions of source credibility of presidential candidates seen in televised debates was explored. The results indicate that perceptions of source credibility were impacted by 
the experience of dimensions of presence, specifically, immersion. However, the candidates were rated as less credible on the larger screen. Additionally. Botta and Bracken (2002) in an experiment manipulating screen size, found that viewers who were exposed to action adventure movie content (Terminator 2, Cameron, 1991), reported more sensations of presence on the larger screen. Further, viewers who reported experiencing one of two presence dimensions (immersion or perceived realism) while viewing had an increased extent to which men reported a drive to be muscular and women reported a drive to be thin.

Although these previous studies demonstrate that television form variables, such as screen size, have been found to play a role in the creation of the sensations of presence experienced by television viewers, there has only been speculation that image quality impacts the amount of presence experienced by television audiences, with improved image quality (higher resolution) leading to greater sensations of presence (Lombard \& Ditton, 1997).

\section{Presence and Image Quality}

Lombard and Ditton (1997) asserted that image quality is a form variable that is likely to impact the extent to which television viewers experience presence. However, to date there has not been a study that linking image quality and experiences of presence. There are few empirical studies conducted on viewers' responses to image quality, in part due to the difficulty of obtaining or creating stimuli, the results are consistent. Specifically, Neuman (1988), in an experiment that examined viewing distance and image quality preference, found that participants who sat closer to the screen preferred high-definition (HD) images to standard definition (NTSC) images. Neuman (1990) found that viewers preferred larger images with any image resolution. However, for 35- and 180-in. displays, the better the image quality was, the more positive the overall reaction was. Reeves, Detenber, and Steuer (1993) examined the effect of image and audio fidelity on attention, memory, and evaluation of content. In a within-subjects experiment, 40 participants viewed 16 one-minute clips from films originally created for cinemas. The participants were exposed to both low-fidelity video (low resolution and low signal-to-noise ratio) and high-fidelity video (high resolution and high signal-tonoise ratio) versions. The findings demonstrated a preference for high-fidelity video but no significant increase in attention or memory.

\section{Presence and Gender Differences}

Across previous research on presence and television, some findings (both causal and correlational) have shown that men and women seem to respond to form changes in different ways. In an experiment manipulating content and screen size (small vs. large; described previously), Lombard et al. (2000) found that female 
participants were more sensitive to differences in screen size than were male participants, with women reporting more presence-related responses than men. Other correlational studies have also found differences in the effects (and experiences) of presence on women and men. In a survey exploring the possible relation between the experience of presence while viewing television and body eating disorders, Botta and Bracken (2004) found that women who reported perceiving television as more realistic (a dimension of presence) also had a higher acceptance of idealized television images (a contributing factor in the development of eating disorders). In contrast, men in the study who reported a higher sense of immersion were more likely to have a higher acceptance of the idealized television image. These results suggest that a gender difference may exist between how women and men respond to experiencing sensations of presence.

\section{HDTV}

HDTV is being introduced as the new standard for television in the United States. What makes HDTV a superior television viewing experience is primarily an improvement in the image quality seen by viewers. The HDTV standard adopted in the United States will provide viewers with up to 1080 lines versus the current NTSC standard of 480 lines on the screen. The United States is also simultaneously converting to digital displays (vs. the current analog standard), so television programming will seem more like watching a DVD versus a VHS tape to the average television viewer. HDTV has been characterized as "video and audio information at a quality level that exceeds that of NTSC, PAL, and SECAM television standards" (Dupagne \& Seel, 1998, p. 47). Another difference is that HDTV uses a 16:9 aspect ratio (widescreen) versus the current NTSC standard of 4:3. This distinction is important because, like seeing a film in the cinema, widescreen television allows the viewer to see more of the mediated environment. Dupagne and Seel asserted that these changes to television form will "accentuate the psycho-physical perception of "telepresence"” (p. 60).

\section{HDTV and the Television Audience}

The general television audience is largely aware of the existence of HDTV. A recent survey conducted by the Cable \& Telecommunication Association for Marketing (2002) found that $60.3 \%$ of Americans were aware of the existence of HDTV. However, only $28.6 \%$ reported ever seeing HDTV. Even so, Americans reported the desire to own television sets with larger screens, most of which are HDTV-compatible (Bracken \& Atkin, 2004). These results are consistent with past studies that have found that when people see HDTV, they rate the picture quality as superior and report an increase in the desire to own a HD-compatible television set. 
Overall, television audiences have reported preferring the improved image quality of HDTV and have expressed an interest in obtaining HD-compatible television sets (Atkin, Neuendorf, Jeffres, \& Skalski, 2003).

\section{Hypotheses}

The preceding literature review provided the foundation of the following hypotheses.

H1: Viewers who watch television in HD will report experiencing a higher level of immersion than viewers who watch television in NTSC.

$\mathrm{H} 2$ : Viewers who watch television in $\mathrm{HD}$ will report experiencing a higher level of spatial presence than viewers who watch television in NTSC.

H3: Viewers who watch television in HD will report experiencing a higher level of social presence-passive interpersonal than viewers who watch television in NTSC.

H4: Viewers who watch television in HD will report experiencing a higher level of perceptual realism than viewers who watch television in NTSC.

H5: Viewers who watch the images in HD will report experiencing a higher level of negative physiological responses than viewers who watch television in NTSC.

RQ1: Does the gender of the television viewer influence the amount of each dimension of presence experienced?

\section{METHOD}

\section{Overview}

This study employed a between-subject $2 \times 2$ (Image Quality $\times$ Gender) experimental design. Ninety-five viewers watched a video clip in either HDTV (1080 lines) or NTSC (480 lines). The images were displayed on the same television (a rear-projection television with a 65 -in. widescreen [16:9] screen). The television was capable of displaying 1080 lines (HD) and also 480 lines (NTSC). Approximately half of the participants watched the video in HDTV (17 men and 25 women), and the other half watched the video in NTSC ( 22 men and 31 females). The participants viewed individually, and the video was switched after every other participant to ensure there was not a difference between the two groups (HD vs. NTSC) based on when they viewed. ${ }^{2}$

\section{Stimulus}

The video shown to the participants was a JVC demonstration tape that was distributed with the JVC HD-DM 30000 D-VHS videocassette recorder entitled The 
Beauty of Japan. The demonstration tape was filmed in and created for playback in HD (D-VHS format). The author created a second copy of the video clip by recording it in NTSC with a down-converting feature of the same VCR. ${ }^{3}$ This particular clip was used because of the difficulty of obtaining stimulus materials in HDTV and the lack of equipment available that allows consumers to record programming currently being aired in HD.

The video clip was $13 \mathrm{~min}$ long and included outdoor and indoor scenes without text or graphics, both of which were likely to remind the viewer that they were watching a created message (Lombard \& Ditton, 1997). The content was footage displaying real people and places in modern-day scenes of rural and urban Japan. The video showed segments of people carrying torches, drinking from cool waterfalls, and preparing tea. The people on the screen were quite prominent in the background, and there were vocalizations, but there was not any discernable dialogue between the actors, just background music.

\section{Participants}

The 95 undergraduate students who participated in the experiment were between 19 and 55 years old $(M=25.9, S D=7.69, M d n=23.0)$. Thirty-nine participants were male, and 56 were female. Sixty-eight percent $(n=65)$ were White, $21.1 \%(n$ $=20$ ) were African American, and the remaining $10.6 \%(n=10)$ were Asian, Pacific Islander, or Hispanic.

\section{Procedure}

Each participant was met by the experimenter and escorted into a carpeted, $8 \times$ 10 -foot room that contained a television, a D-VHS videocassette recorder, and a comfortable chair that faced the television screen. Various other amenities, such as a decorative table lamp and pictures on the wall, allowed the participant to feel as if they were in a living room. In both conditions, the chair was placed 6 feet from the front of the screen. ${ }^{4}$

The experimenter explained to the participants that they would be watching a 13-min video clip and that after the video clip was over they would be brought to another room to complete a questionnaire. The second room contained two tables and two chairs. The experimenter instructed the participant to sit at one of the tables and to answer a paper-and-pencil questionnaire. The experimenter emphasized that there were no wrong answers and that the participant should follow the directions in the questionnaire. The entire procedure took about $35 \mathrm{~min}$.

\section{Dependent Measures}

Immersion. Participants responded to a 7-point scale with some Likert-type and other Semantic Differential scales. The items were adapted from Lombard and 
Ditton (2001) and Lessiter, Freeman, Keogh, and Davidoff (2001) to measure the extent to which television viewers felt a sense of involvement or connection when they watch television programs and movies. The six questions or statements were: "How involving was the media experience?" "How completely were your senses engaged?" "To what extent did you experience a sensation of reality?" "I lost track of time," "I felt that the displayed environment was part of the real world," and "I felt surrounded by the displayed environment." Cronbach's alpha for the additive index was .81 .

Spatial presence. Participants responded on a 7-point Likert-type scale for three questions designed by Lombard and Ditton (2001) to measure the extent to which viewers experienced a sense of sharing a physical space. The three questions were: "How much did it seem as if the objects and the people you saw/heard had come to the place you were?" "How much did it seem as if you could reach out and touch the objects or people you saw/heard?" and "How often when an object seemed to be headed toward you did you want to move out of its way?" Cronbach's alpha for the additive index was .70.

Social presence-passive interpersonal. Participants responded from 1 (not well) to 7 (very well) on a Likert-type scale for two questions designed by Lombard and Ditton (2001). The questions measured the extent to which viewers could sense characters' behaviors on television. The two questions were "During the media experience how well were you able to observe the facial expressions of the people you saw/heard?" and "During the media experience how well were you able to observe the body language of the people you saw/heard?" Cronbach's alpha for the additive index was .78.

Social realism. Participants responded on a 7-point Likert-type scale for three questions designed by Lombard and Ditton (2001) to measure the extent to which television viewers feel that television programming is an accurate portrayal of reality. The three statements were "The events I saw/heard would occur in the real world." "The events I saw/heard could occur in the real world," and "The way the events I saw/heard occurred is a lot like the way they occur in the real world." Cronbach's alpha for the additive index was .87 .

Perceptual realism. Participants responded from 1 (not at all) to 7 (very much) on a Likert-type scale for six questions designed by Lombard and Ditton (2001) to measure the extent to which television viewers feel a sense realism when viewing television. The six questions were "How much did the things/people in the environment you saw/heard SOUND like they would if you experienced them directly?" "How much did the things/people in the environment you saw/heard LOOK like they would if you experienced them directly?" "How much did the 
things/people in the environment you saw/heard SMELL like they would if you experienced them directly?" "How much did the things/people in the environment you saw/heard FEEL like they would if you experienced them directly." "How much did the heat or coolness (temperature) of the environment you saw/heard feel like they would if you experienced them directly?" and "How much did you feel like the events you saw/heard were happening to you?" Cronbach's alpha for the additive index was .85

Physiological presence responses. Participants responded from 1 ( $a b$ sent) to 4 (severe) for five questions designed by Lombard and Ditton (2001) to measure the extent to which television viewers feel negative physiological effects. The five questions were "To what degree did you experience stomach awareness during the media experience?" "To what degree did you experience nausea during the media experience?" "To what degree did you experience dizziness with your eyes open during the media experience?" "To what degree did you experience dizziness with your eyes closed during the media experience?" and "To what degree did you experience and increased adrenaline rush?" Cronbach's alpha for the additive index was .72 .

\section{RESULTS}

Separate two-way analyses of variance with image quality and gender as independent variables were conducted for each of the hypotheses.

Some evidence was found for $\mathrm{H} 1$, which predicted that viewers who watched the HDTV images would report feeling more immersed than viewers who watched the NTSC television images, $F(1,95)=3.35, p=.06$ (see Table 1). Participants who viewed the HD television images $(M=4.17, S D=1.24)$ reported feeling more immersed than viewers who watched the NTSC television images $(M=3.71, S D=$ 1.20).

$\mathrm{H} 2$, which predicted that television viewers who watched the images in HD would report experiencing a higher level of spatial presence was supported, $F(1$, $95)=4.18, p=.04$ (see Table 1), with viewers who watched HD television images $(M=2.93 . S D=1.34)$ reporting greater feelings of spatial presence than NTSC television viewers $(M=2.38, S D=1.22)$.

H3, which predicted that television viewers who watched the images in HD would report experiencing a higher level of social presence-passive interpersonal was supported, $F(1,95)=4.19, p=.04$ (see Table 1). The viewers who watched HD television images ( $M=3.47, S D=1.12$ ) reported more social presence-passive than NTSC television viewers $(M=2.92, S D=1.39)$.

$\mathrm{H} 4$, which predicted that television viewers who watched the images in HD would report experiencing a higher level of perceptual realism, was significant, 
TABLE 1

Analyses of Variance

\begin{tabular}{|c|c|c|c|c|}
\hline Source of Variation & SS & $d f$ & $M S$ & $F$ \\
\hline \multicolumn{5}{|c|}{ Image quality and gender on immersion } \\
\hline \multicolumn{5}{|c|}{ Main effects } \\
\hline Image quality & 5.05 & 1 & 5.05 & $3.35^{*}$ \\
\hline Gender & 0.66 & 1 & 0.66 & 0.44 \\
\hline \multicolumn{5}{|l|}{ Two-way interaction } \\
\hline Image Quality $\times$ Gender & 0.04 & I & 0.04 & 0.03 \\
\hline \multicolumn{5}{|c|}{ Image quality and gender on spatial presence } \\
\hline \multicolumn{5}{|c|}{ Main effects } \\
\hline Image quality & 6.84 & 1 & 6.84 & $4.18 * *$ \\
\hline Gender & 2.79 & 1 & 2.79 & 1.70 \\
\hline \multicolumn{5}{|l|}{ Two-way interaction } \\
\hline Image Quality $\times$ Gender & 0.002 & 1 & 0.002 & 0.001 \\
\hline \multicolumn{5}{|c|}{ Image quality and gender on social presence-passive interpersonal } \\
\hline \multicolumn{5}{|c|}{ Main effects } \\
\hline Image quality & 10.85 & 1 & 10.85 & $4.16^{* *}$ \\
\hline Gender & 0.98 & 1 & 0.98 & 0.38 \\
\hline \multicolumn{5}{|l|}{ Two-way interaction } \\
\hline Image Quality $\times$ Gender & 0.84 & 1 & 0.84 & 0.057 \\
\hline \multicolumn{5}{|c|}{ Image quality and gender on perceived realism } \\
\hline \multicolumn{5}{|c|}{ Main effects } \\
\hline Image quality & 6.88 & 1 & 6.88 & $3.41 *$ \\
\hline Gender & 8.25 & 1 & 8.25 & $4.06^{* *}$ \\
\hline \multicolumn{5}{|l|}{ Two-way interaction } \\
\hline Image Quality $\times$ Gender & 2.58 & 1 & 2.58 & 1.28 \\
\hline \multicolumn{5}{|c|}{ Image quality and gender on physiological responses } \\
\hline \multicolumn{5}{|c|}{ Main effects } \\
\hline Image quality & 0.46 & 1 & 0.46 & $3.50^{*}$ \\
\hline Gender & 0.18 & 1 & 0.18 & 1.40 \\
\hline \multicolumn{5}{|l|}{ Two-way interaction } \\
\hline Image Quality $\times$ Gender & 0.009 & 1 & 0.009 & 0.07 \\
\hline
\end{tabular}

$* p<.10 . * p<.05$.

$F(1,95)=4.19, p=.04$ (see Table 1 ). The viewers who watched the video in HD reported more of a sense of perceptual realism $(M=3.92, S D=1.45)$ than those viewers who watched the video in NTSC $(M=3.31, S D=1.44)$.

Some support was found for $\mathrm{H} 5$, which predicted that television viewers who watched the images in HD would report experiencing a higher level of negative physiological responses, $F(1,95)=3.50, p=.06$ (see Table 1). Viewers who watched the program in HD reported experiencing more negative physiological responses $(M=1.32, S D=0.46)$ than the viewers who watched the video in NTSC $(M=1.18, S D=0.25)$. 


\section{Gender}

There was not a difference found for a main effect of gender on the majority of presence dimensions. The one exception was a significant main effect for gender, $F(1,95)=4.19, p=0.04$, with women reporting more perceived realism $(M=3.82$, $S D=1.49)$ than men $(M=3.25, S D=1.39$; see Table 1$)$. Additionally, there was not a significant difference for the interaction between image quality and gender.

\section{Additional Analyses}

HDTV is said to provide a superior picture. An independent-sample, nondirectional (i.e.., two-way) $t$ test was conducted to test the participants' perceptions of picture quality with actual image quality (HD vs. NTSC) as the independent variable. Participants who viewed the HD television images reported that the picture quality was higher $(M=6.43, S D=1.17)$ than viewers who watched the NTSC images $\left(M=5.11, S D=1.71 ; t=-4.26 . p=.001, \eta^{2}=.163\right)$.

Additionally, the amount of television viewing was tested to see if it played a role in viewers' experiences of presence. The participants were asked about the amount of television they watched on both a weekend and a weekend day. The amounts were weighted and averaged to create an average viewing day. The average television viewing variable was included in the analysis of variance as a covariate. For all of the presence variables, regular television viewing amounts was not a factor in viewers' experience of presence dimensions, nor was the size of the television viewed most often.

\section{DISCUSSION}

These results suggest that image quality does indeed influence the amount of presence reported by television viewers, confirming previous speculation (Lombard \& Ditton, 1997). There were significant differences or differences that approach significance for all five of the presence dimensions tested. thus presenting a clear case that improved image quality increases the amount of presence sensations experienced by HDTV viewers. The results also suggest that television viewers will experience a greater level of presence and a wider variety of presence dimensions when the conversion to HDTV is completed.

These findings provide support for the assertions of previous researchers (Lombard \& Ditton, 1997; Lombard et al., 2000), who suggested that television form plays a role in evoking a sense of presence in television viewers. Additionally, the results of this study support the previous assertion that form variables can influence 
sensations of presence (Lombard \& Ditton, 1997) and specifically provide evidence that changes in image quality can impact television viewers' sense presence.

In particular, the higher levels of immersion reported by viewers in the HD condition suggest that they were more involved with the content, and the use of neutral content in this study suggests that viewers will be even more immersed in the content they select and view on a regular basis. Related to immersion, the dimensions of spatial presence and the differences in the levels of reported physiological responses between the conditions (HDTV vs. NTSC) suggested that audiences do feel a sensation of being in a shared mediated space and. further, that they may have (negative) physiological responses to the mediated environment. The difference in the experience of physiological responses in the HDTV condition also suggests that image quality contributes both to a sensation of presence dimensions and to the physical consequences of such experiences. Some of the physical consequences may lead viewers avoid content with lots of camera movement or cuts, especially viewers who are prone to motion sickness.

The findings of the social presence-passive interpersonal dimension were interesting, as this dimension inquired largely about the nature of the characters or people in the mediated environment. Although the video was mainly comprised of scenes with people interacting in the background. the actors' body movement was visible, allowing the viewers to identify individuals and their nonverbal expressions. The HD viewers reported being able to observe the people's facial expression and body movement on the screen significantly better than the viewers who watched the same scenes in NTSC. Again, the improved image quality of HDTV provided audiences with the opportunity to see more of the action (in this case) nonverbal communication, and therefore, perhaps they perceived the television environment as one that could approximate a nonmediated interaction.

Evidence that gender played a role in the experience of dimensions of presence was only found for the perceptual realism dimension (a finding consistent with previous findings on body-image disturbance; Botta \& Bracken, 2004). This is particularly interesting because the content was footage displaying real people and places and because women reported that the content seemed more perceptually real; it may be that women evaluate some types of nonfictional television content as more real than men. This also suggests that the same may be true for fictional programming.

These results are important because the selling point used by television manufacturers for HDTV is that viewers will feel as if they are "there" or part of the action. For example, the ESPNHD (2004) Web site (the ESPN HD channel) states "with a dramatic widescreen picture so clear, you'll feel like you are actually at the game." Additional research is needed to better understand viewers' experiences of presence dimensions with varying content and to investigate whether and how women are affected by presence differently than men. The results also suggest that 
the distinction between television content and form (screen size, image quality) needs to be further examined.

The results of this study are tempered by the limited content available at the time the study was conducted. Specifically, the nature of the video clip with its limited interaction of characters did not allow for the testing of other social presence dimensions. Additionally, the physiological response measures in this study were posttest subjective measures and did not include any concurrent measurements.

\section{CONCLUSION}

Improved image quality did influence the amount of presence reported by television viewers. The results also suggest that as more people purchase and watch HDTV, we will see an increase in the both the number of presence dimensions and the frequency of such sensations being experienced in home viewing environments. Furthermore, because previous research suggests that presence plays a role in the strength of other media effects. these findings seem to indicate that levels of media effects may be on the increase. The results also suggest that this increase in media effects may impact female viewers more than male viewers.

\section{ACKNOWLEDGMENTS}

This project was partially funded by the Cleveland State University New Faculty Research Development Award. An earlier version of this article was presented to the Information Systems division at the 2002 annual conference of the International Communication Association, Seoul, Korea.

\section{NOTES}

\footnotetext{
${ }^{1}$ These conceptualizations include (a) presence as immersion, which refers to the extent of perceptual and psychological immersion in a mediated environment; (b) presence as transportation, such that the viewer is transported into the mediated environment ("you are there") or that the mediated environment seems to intrude into the viewer's environment ("it is here") or two users seem to meet in a shared mediated space ("we are together"); (c) presence as social actor within a medium or the idea that a viewer responds to social cues presented by the people or characters that they encounter through a medium, although no real-time interaction is possible (e.g., parasocial relationships); (d) presence as social richness or the extent to which a medium is perceived as sociable, warm, sensitive, personal, or intimate; and (e) presence as realism, or the extent to which a medium can produce seemingly accurate representations of objects, events, and people.

${ }^{2}$ There was a short period where the D-VHS unit was unable to playback in HD and participants viewed only the NTSC.
} 
${ }^{3}$ The HD version for the clip was displayed in a 16:9 aspect ratio, whereas the NTSC version was displayed in a $4: 3$ aspect ratio with unobtrusive black space on the right and left sides.

${ }^{4}$ The field of view for the HD condition was $44.8^{\circ}$, and for the NTSC condition, it was $41.2^{\circ}$.

\section{REFERENCES}

Atkin, D., Neuendorf, K., Jeffres, L., \& Skalski, P. (2003). Predictors of audience interest in adopting digital television. Journal of Media Economics, 16, 159-173.

Barfield, W., \& Weghorst, S. (1993). The sense of presence in virtual environments: A conceptual framework. In G. Salvendy \& M. Smith (Eds.), Human-computer interaction: Applications and case studies (pp. 699-704). Amsterdam: Elsevier.

Biocca, F., \& Delaney, B. (1995). Immersive virtual reality technology. In F. Biocca \& M. R. Levy (Eds.), Communication in the age of virtual reality (pp. 57-124). Hillsdale, NJ: Lawrence Erlbaum Associates, Inc.

Botella, C., Baños, R. M., \& Alcañiz, M. (2003, October). A psychological approach to presence. Paper presented to the sixth annual presence workshop, Aalborg, Denmark.

Botta, R. A., \& Bracken, C. C. (2002, November). Muscle bound: Men, muscularity, and social comparisons. Paper presented at the Mass Communication Division of the annual meeting of the National Communication Association, New Orleans, LA.

Botta, R. A., \& Bracken, C. C. (2004). Examining the influence of television image idealism and presence on men's and women's drives to be thin and muscular. Unpublished manuscript.

Bracken, C. C., \& Atkin, D. (2004). A survey of presence evoking technology in our living room. Visual Communication Quarterly, 11, 23-27.

Bracken, C. C., Neuendorf, K. A., \& Jeffres, L. W. (2003, August). Screen size, source credibility, and presence: Audience reactions to the televised 2000 presidential debates. Presented to the Communication Theory and Methodology Division at the annual conference of the Association for Education in Journalism and Mass Communication, Kansas City, MO.

Burch, N. (1979). To the distant observer: Form and meaning in the Japanese cinema. London: Scolar.

Cable \& Telecommunication Association for Marketing. (2002, June). HDTV: I've heard of it, But what is it? Pulse. Retrieved July 17, 2002, from http://www.ctam.com/ctam/members_only/getpdf. cfm? name=pulse0602.pdf

Cameron, J. (Director). (1991). Terminator 2-Judgment day [Motion picture]. United States: Columbia Tristar.

David, P. (2004, May). Presence theory in the realm of social interaction with technology: Computers, computer agents, and beyond. Paper presented to the Information Systems Division at the annual conference of the International Communication Association, New Orleans, LA.

Dillon, C., Keogh, E., Freeman, J., \& Davidoff, J. (2001, May). Presence: Is your heart in it? Paper presented to the fourth annual international workshop on presence, Philadelphia.

Dupagne, M., \& Seel, P. B. (1998). High-definition television: A global perspective. Ames: Iowa State University Press.

ESPNHD. (2004). Retrieved January 10, 2004, from http://espn.go.com/

Kim, T., \& Biocca, F. (1997). Telepresence via television: Two dimensions of telepresence may have different connections to memory and persuasion. Journal of Computer-Mediated Communication, 3(2). Retrieved August 2, 2002, from http://www.ascusc.org/jcmc/vol3/issue2/kim.html

Krugman, H. E. (1983). Psychological characteristics of high-definition television. Address presented at the American Association for Public Opinion Research, Buck Hill Falls, PA.

Lee, K. M. (2004). Presence, explicated. Communication Theory, 14, 27-50.

Lessiter, J., Freeman, J., Keogh, E., \& Davidoff, J. (2001). A cross-media presence questionnaire: The ITC-sense of presence inventory. Presence, 10, 282-297. 
Lombard, M. (2000, July). Resources for the study of presence: Presence explication. Retrieved January 5, 2004, from http://www.temple.edu/ispr/frame_explicat.htm

Lombard, M., \& Ditton, T. B. (1997). At the heart of it all: The concept of presence. Journal of Computer-Mediated Communication, I3(3). Retrieved June 16, 2002, from http://www.ascusc.org/jcme/ vol3/issue $2 /$ lombard.html

Lombard, M., \& Ditton, T. B. (2001). Measuring presence: A literature-based approach to the development of a standardized paper and pencil instrument. Paper presented at Presence 2001: The third international workshop on presence, Philadelphia.

Lombard, M., Ditton, T. B., Grabe, M. E., \& Reich, R. D. (1997). The role of screen size in viewer responses to television fare. Communication Reports, 10, 95-106.

Lombard, M., Reich, R. D., Grabe, M. E., Bracken, C. C., \& Ditton, T. B. (2000). Presence and television: The role of screen size. Human Communication Research, 26, 75-98.

Minsky, M. (1980, June). Telepresence. Omni, pp. 45-51.

Neuman, W. R. (1988, April). The mass audience looks at HDTV: An early experiment. Paper presented at the annual convention of the National Association of Broadcasters, Las Vegas, NV.

Neuman, W. R. (1990). Beyond HDTV: Exploring subjective responses to very high definition television (Research report). Cambridge: Massachusetts Institute of Technology Media Lab.

Reeves, B., Detenber, B., \& Steuer, J. (1993, May). New televisions: The effects of big pictures and big sound on viewer responses to the screen. Paper presented at the Information Systems Division at the annual meeting of the International Communication Association, Washington, DC.

Schubert, T., Friedman, F., \& Regnebrecht, H. (2001). The experience of presence: Factor analytic insights. Presence: Teleoperators and Virtual Environments, 10, 266-281.

Sheridan, T. B. (1992). Musing on telepresence and virtual presence. Presence: Teleoperators and Virtual Environments, 4, 64-80.

Slater, M., \& Wilbur, S. (1997). A framework for immersive virtual environments (FIVE): Speculations on the role of presence in virtual environments. Presence: Teleoperators and Virtual Environments, $6,603-616$.

\section{Post-print standardized by MSL Academic Endeavors, the imprint of the Michael Schwarts Library at Cleveland State University, 2017}

